\title{
Influence of Cloud Based Mobile Learning Applications on User Experiences: A Review Study in the Context of Jordan
}

\author{
https://doi.org/10.3991/ijim.v11i4.6938 \\ Osama Harfoushi \\ The University of Jordan, Amman, Jordan \\ o.harfoushi@ju.edu.jo
}

\begin{abstract}
Following the increasing trend of cloud computing and mobile applications, the use of cloud based mobile learning applications is also mounting. Almost every e-commerce service provider offers cloud based mobile learning applications so that they can target more visitors and ultimately increase their sales. The usability of cloud based mobile applications is not only grounded in e-commerce platforms but it also ease out mobile learning processes. Most of the educational institutes are now offering cloud based mobile applications so that their students can navigate their knowledge portal more easily and download relevant materials or submit assignments. The main research area of this article is to explore how cloud based mobile learning applications can be utilized more effectively and its impact on the users. In addition it compares the mobile learning methods versus traditional learning methods. The study is done in Jordan and the major part of the research is carried out through reviewing literature, reports, books, national and international databases. Literature review shows that mobile cloud computing is getting popularity in Jordan and have significant impact on mobile learning of Jordanian students. Further, Mlearning indeed an innovative tool for learning and it helps the users in many ways. Findings of this study are helpful for the educational institution and they will learn about cloud based mobile applications user experiences.
\end{abstract}

Keywords-Cloud Computing, Mobile Applications, Cloud based Applications, Mobile Learning and Mobile Commerce

\section{Introduction}

The growing demand for latest technology has forced the industries related to information technology to introduce more new innovative technologies. IT (Information Technology) sector is not confined to one country, it has expanded itself across the world. The new form of communication technology is one of the most significant achievements of science and technology. Moreover, information technology has changed various sectors of the society either its corporate or government offices. The communication system has helped the organizations to perform better and run the 
business smoothly. Since the inception, the IT sector has been constantly changing itself.

Mobile phone technology and other Smart technology is one of the best achievements of today's era. Mobile technology becomes an important necessity of everyday life. It enables one to use it either in the office, home, or whilst traveling. Thus, the mobile technology works everywhere with wireless connections. Smartphone technology along with various mobile applications are now very helpful for the users. These applications are a source of information for the general public. Every day a new application emerges and enables the users to utilize it in their life.

In this research, a new form of technology 'cloud computing' will be analyzed and also assess its effectiveness with mobile technology. In addition, MCC is also a very important phenomenon where the users can to save their non-physical data outside their mobile. The most popular storage applications for MCC is Google drive. This allows one to save data in the drive and can be accessed from anywhere and anytime. Now, with the availability of the Internet, users can check their data on the drive from any smart mobile or computers. It protects their data and confidential files are secure on the servers.

This research dealt with the use of MCC and Mobile Learning in the context of Jordan. In the Arab world, Jordan has achieved great success in the IT sector. Additionally, this information technology has revamped its education sector. Mobile learning is getting popular day by day because of the Smartphone technology in amalgamation with cloud computing. Indeed, mobile learning empowers the users and allows them to learn a variety of things whenever they want. The learning process is not confined to one topic or discipline, there are many applications, which are helpful in the academic life.

The mobile learning through mobile computing is not much expensive and is affordable for students to read a book, notes, and other materials. The mobile learning process is a vast concept, a user can learn from various resources such as online books, videos, and audio lectures. Similarly, a user can get the lecture of any renowned professor through mobile applications. The compact size of mobile phones enable the users to carry it anywhere and help them to learn whenever they want. It is quite difficult to carry books everywhere, whereas this MCC technology makes life easier for the users of all ages. With the mobile learning, there is no time constraint for the users.

What is the role of cloud based mobile learning application on Jordanian students? How cloud based mobile applications are better in comparison with traditional learning methods? The broad aim of the study is to explore how cloud based mobile learning applications can be utilized more effectively and what impact they imply on its users. Also to compare the cloud based mobile learning methods with traditional learning methods in the context of Jordan. Besides, this study will also explore the advantages of mobile learning and how it has obsolete the traditional learning process in the educational sectors of Jordan. This study further aims to analyze the factors that are paving the way to mobile learning in Jordan and how the users are accepting the new trends of MCC and learning. 


\section{$2 \quad$ Literature Review}

This part of the research includes reviews of research works of different scholars. Moreover, the literature that are reviewed for this section includes practical researches in the field of Mobile learning and latest Cloud computing technology. Besides, this section further includes topics related to Information technology, m-learning in Jordan, MCC and other works which come under the M-learning.

\subsection{Cloud Computing}

The existence of mobile technology makes the life very easy for the users. It ensures fast communication system without any obstacle. The Smartphone technology along with other gadgets like tablets and androids are increasing rapidly. The most common topic which is bandied in the field of information technology these days is, 'Cloud Computing'. Particularly in the field of web, developers and IT professionals use this terminology [1]. These days, owing to globalization, there are many benefits of using cloud computing. Generally, a provider of cloud computing technology delivers applications related to common business as services. However, these applications are further accessed by software's commonly known as the web browser and the data is stored in the server [2].

Moreover, the foundation of the system of cloud computing is based on the abstraction of computing and storage infrastructure. Cloud computing in the current era is a famous service in the information technology sector which is based on two domains, such as distributed computing and other is virtualization. The traditional or old application silos can be removed by cloud computing and it gives new scalability to the organizations related to information technology [3]. One of the most famous and attractive technologies in the field of Information technology is 'cloud computing'. It supports to the services infrastructure and also to the software. That's why it is attracting a large number of specialists of IT towards it. The recent trends in the information technology and internet have changed the demand for the users. Every day a new technology emerges and constantly changing day by day. Basically, a cloud computing is a phenomenon in which a person uses computing resources delivered by the internet [4].

\subsection{Mobile Cloud Computing}

Alghabban and his group conducted a research on 'MCC and M-Learning: State of Art' in which the researcher explores the importance of latest mobile learning technology [5]. Under the MCC, the main application which comes under it, is the mlearning, m-commerce, and much more. It's the best way to impart knowledge and it also gives awareness to the masses around the world. He further investigated that mobile learning has more impacts on the students than the influence of traditional learning. In mobile learning, a student is able to watch videos along with written material and audio lectures. Thus, it's an innovative learning technique of the 21 st century. 
MCC not only gives benefits to the students but it also provides effective opportunities to the employees of any organization. It's an excellent source of information and helps in various circumstances. However, in the field of education, it has a vast scope [6]. The use of online textbooks has increased because of the Smartphone and access to wireless networks. The MCC stores the data for the students and helps in learning.

Boyinbode and Akintade conducted a survey 'security frameworks for mobile cloud computing' in which the researchers explore MCC and its implications through security framework [7]. The study investigates that data security in the MCC needs more security and strong IT system.

The growing use of mobile applications in the multi-media has increased the importance of MCC because it enables the users to store their data. There is a rapid growth in the field of cloud computing. Smartphone technology ensures easy access to the services via mobile computing. A MCC refers to the system in which Smartphone or other mobile devices get easy access to other computing resources.

\subsection{Mobile Learning Applications and Services}

Indeed, mobile phone particularly smart technology has a significant position in human's life, the continuous use of Smartphone invites other computing technology to run its functions more effectively. It is natural when a person sits alone, he or she prefers to use mobile. Therefore, if a person gets access to the wireless internet then he or she prefers to read something on the mobile. In the field of smart technology, cloud plays an important role in the implementation of applications and it provides complete services [8].

Cloud Computing transforms the physiognomies by using virtualization in the sector of information technology. There are many mobile applications under cloud computing which are working these days such as Instagram, Google apps, and Twitter. These applications have transformed the communication process and technology as well. One of the biggest benefits of the cloud computing is, it provides data service integration in a better form by utilizing other resources. It further helps the data security in a better way at less costly method.

It enhances the efficiency of mobile users and cloud computing technology as well. The most popular and growing storages of MCC these days are iCloud, Dropbox, and Google drive [9]. These storages are very helpful for the users and in this way they secure their data as well. All across the world, people use these storages and share their data without any obstacle. These storages are not costly and just require wireless internet connections. The users of Smartphone technology can add and delete the data from these storages whenever they want. The data which is stored in these storages can't be visible to anyone. Thus it ensures the privacy and also hides the confidential data in it [10].

The storing of the data in the cloud computing storages has various benefits. It enables the users to view their files and documents from any computer, mobile or tablets via an internet connection. Moreover, the mobile cloud technology has an ability to secure backup files. Thus, in a case of mobile or computer crash, the data remains 
safe in the storages. Therefore, the rise in the Smartphone technologies invites more applications in the field of information technology. These applications run on a Smartphone with access to the internet. Mobile data computing refers to an advanced technology in which a user saves its data outside the mobile after processing the data. Therefore, in other words, it's a process of securing a data outside the mobile [3].

Table 1. Literature Table

\begin{tabular}{|l|l|l|l|l|}
\hline Year & \multicolumn{1}{|c|}{ Author Name } & \multicolumn{1}{c|}{ Title } & \multicolumn{1}{c|}{ Objectives } & \multicolumn{1}{c|}{ Findings } \\
\hline 2014 & AFOLABI A.O & $\begin{array}{l}\text { On MCC in a Mobile } \\
\text { Learning System }\end{array}$ & $\begin{array}{l}\text { To promote m- } \\
\text { learning with help of } \\
\text { MCC }\end{array}$ & $\begin{array}{l}\text { Traditional learning has } \\
\text { obsolete by m-learning that } \\
\text { provides fast learning }\end{array}$ \\
\hline 2016 & $\begin{array}{l}\text { Weam Gaoud } \\
\text { Alghabban }\end{array}$ & $\begin{array}{l}\text { MCC and M- } \\
\text { Learning: State of Art }\end{array}$ & $\begin{array}{l}\text { To find the gaps in } \\
\text { the previous re- } \\
\text { searches related to } \\
\text { mobile computing }\end{array}$ & $\begin{array}{l}\text { Mobile learning is more } \\
\text { popular than traditional } \\
\text { Data storage empowers the } \\
\text { users }\end{array}$ \\
\hline $\begin{array}{l}\text { H., \& Ramachan- } \\
\text { dran, M. }\end{array}$ & $\begin{array}{l}\text { Adoption Framework } \\
\text { (CCAF): A security } \\
\text { framework for busi- } \\
\text { ness clouds. }\end{array}$ & $\begin{array}{l}\text { To highlight the } \\
\text { importance of CCAF } \\
\text { security in Cloud } \\
\text { Computing }\end{array}$ & $\begin{array}{l}\text { CCAF system ensure securi- } \\
\text { ty for the data. } \\
\text { Security concerns can be } \\
\text { removed by CCAF }\end{array}$ \\
\hline 2017 & Vanessa Ratten & $\begin{array}{l}\text { MCC: innovation and } \\
\text { creativity perspectives }\end{array}$ & $\begin{array}{l}\text { To show the innova- } \\
\text { tion in MCC and } \\
\text { comparison between } \\
\text { traditional and new } \\
\text { MCC }\end{array}$ & $\begin{array}{l}\text { Innovation in MCC im- } \\
\text { proves the organizational } \\
\text { performance }\end{array}$ \\
\hline
\end{tabular}

\subsection{Mobile learning in Jordan}

Al-Adwan and Smedley has examined a study on the mobile learning demand in the cities of Jordan [6]. In his research, 'Implementing e-learning in the Jordanian Higher Education System: Factors affecting impact', the researcher explored the process of e-learning and mobile learning in Jordan. The results of the study show that the modes of technology in the learning process is a key tool to success. He further explored that in the start of the 21 st century, for communication purposes, email process was used in the educational sectors. Currently, the latest mobile learning technology empowers the students in a better way.

The mounting demand for the latest technology in today's world increases the demand for education as well. To equip the masses with education, the latest technology is required. People around the world demand for better education, similarly in Jordan, students want new modes of learning [11]. Jordan is situated in the Middle East and has gained much progress in the field of education by using advanced modes of learning. Information technology supports every sphere of life. Thus the education sector of Jordon also demands change in the learning process because of IT.

Undoubtedly, the entrance of Mobile learning in Jordon's education sector has transformed the learning and teaching practices. In Jordan, the demand for wireless internet has been increasing for last many years and it is the most important factor in the expansion of mobile learning process. Moreover, in the near future, there is a 
chance of the development of the mobile semiconductors technology like flash memory [12]. It will change the mobile devices into more small size so that a user can read the content easily.

The 21 st century is said to be the century of IT. In this era, everyone is seeking the new ways of obtaining knowledge. The rapid transformation in the IT sector of Jordan has transformed the education sector also [13]. Mobile learning becomes a very important component of learning in Jordan. Mobile learning has already developed the education level of the country and also helps the new generation in their learning. The education provided through the mobile is not confined to classrooms or to the institute.

Basically, mobile learning in Jordan encompasses both mobile computing and elearning. It's an extension or further development of e-learning [14]. It helps in broader learning through a powerful method. The concept of m-learning has been gaining popularity for last decade because of cloud computing. In this way, a student or a person from a rural part of the society gets better knowledge without any cost [15].

Mobile learning usually functions when a student is away from the class room. Mobile learning in Jordan is gaining popularity because of flexibility of the device. Owing to the compact size of mobile devices, users feel comfortable [16].

The m-learning in the education sector of Jordan has achieved significance importance and becomes popular as a unique way of learning. It provides various academic resources, contents, and other services to the users via an internet connection. This digital learning has altered the education sector into an entirely new age. It provides the users more effective learning at cheap prices [17].

As far as students are concerned, the MCC helps in downloading books and other academic resources. A student can save its academic data in the MCC system. It's a new technology of the $21^{\text {st }}$ century and has various benefits for the people of all ages particularly for the students [18]. One of the most effective benefits of it is, it doesn't require any other hardware and software. That's why the majority of the students prefer to use it because it stores academic notes in the application running on it.

Besides, it enhances the efficiency of the education system which leads to improvement in the quality of education. It uses cloud computing in the mobile to deliver other application in the smart phones. Basically, MCC is a combination of various networks such as cloud computing, wireless networks / the internet and mobile computing. It gives computational resources for the users of Smartphone. In many cases, higher applications such as IBM, Google, and Microsoft give the Cloud to the education system free of cost [11]. In this way, it gives benefits to the students and to the education sector of the society as well.

Hashemi and his team conducted an empirical research on 'What is Mobile Learning? Challenges and Capabilities' which shows that the users of mobile have increased to almost 1.7 billion users around the world and the demand for mobile learning is also increasing [10]. A student gets more attraction towards the mobile learning than eLearning. Mobile learning provides a better chance of learning for the students. Apart from students, teachers also obtain more knowledge through the platform of mobile learning. The findings of this research highlight the importance of mobile 
learning. It elucidates that it's the most acceptable and a new tool in the world of technology. It enables the students to obtain knowledge easily and it has also obsolete the traditional learning methods.

With easy access to mobile and the internet, students prefer to learn through multimedia such as video, audio, and other online activities on mobile. In this way, mobile learning enables a student to get knowledge according to their requirement. A student gets more attraction towards studies when he or she has complete access to knowledge. With access to e-learning, mobile applications allow a student in getting continuity of learning. This leads to a better outcome in the result form. It helps to both the trainers and the learners as well [14]

Masud and Huang has conducted a study on 'A Cloud Based M- learning Architecture for Higher Education' [19]. In which they highlighted the benefits of M-learning and how it obsoletes the traditional ways of learning. The findings of the research showed that mobile technology with the amalgamation of cloud computing has enriched the learning process of the current era. Moreover, it's a low-cost learning strategy which enables the students more empowered.

It is useful, because by using it a person doesn't need other expensive software's and computing hardware's. It helps in conveying the information and also increases the growth of multi-media applications. Owing to the technological innovations, cloud computing transforms other information technology related to communication which enables the computing to occur effectively. The competition in the IT industry also changes because of the entry of cloud computing which provides better accessible services [4].

\subsection{Comparison of M-Learning and Traditional Learning}

Mobile learning is a broader term which refers to the acquisition of knowledge by using Smartphone technology [20]. The rise of mobile application and cloud computing has paved the way to a new technology ' $\mathrm{MCC}$ '. It is an effective technology in the current era for the mobile users. It provides an infrastructure by which a person can store his data outside of mobile. Now the obstacles of security issues, battery life etc. are not big issues. Because by MCC, the data is secured in other applications. The integration of mobile computing into the mobile technology has transformed the learning process [21].

Boyinbode and Akintade conducted a research on 'a cloud-based mobile learning interface' which shows that mobile learning is a quick way of learning for the young generation [7]. MCC provides an infrastructure outside to the mobile device where the data processing and storage happens. Mobile subscribers can avail this opportunity if they have a smart technology and the internet. It's a widespread technology which aims to empower the users by giving them storage accessibility. Though in Jordan it is a new technology and will take more time for expansion. The reason is that many people do not have access to the internet or have smart phone technology.

In the education sector, mobile learning is a game changer that offers equal access to education and learning for all students around the world. Mobile learning in the current scenario is the delivery of education and training on Smartphone devices. This 
technology allows the users to acquire knowledge virtually whenever they want at any place [12]. It's quite different from the eLearning and a more transformed form of eLearning.

Recently, Ratten conducted a research on 'MCC: innovation and creativity perspectives' which explores that the rapid use of mobile technology has increased the demand for MCC [8]. Mobile technology enables the users to be aware of everything that is happening in the world. This study further explores that MCC is an innovative technology and is very important in the professional sector. In this chapter, the literature which was reviewed and highlighted the importance of mobile learning these days. It enhances the learning process for the users and in the future, it will further progress.

\section{Conclusion}

The technology in the current era is constantly changing and the demand for the Smartphone is also increasing. The new features of Smartphone have attracted a large number of users around the world. This leads to the rise in the demand for m-learning and it has a tendency to change the education system in the society.

E-learning indeed an innovative tool for learning and it helps the users in many ways. In traditional learning, students used to spend their money on books and other written materials. However, the mobile learning has made life easy and feasible. It enhances the knowledge of a common man and also empowers the users. The features of mobile phones change the patterns of other applications as well and constantly changing day by day. It also needs more strong information technology to run its functions. The Mobile Computing System provide strong storage applications to the users. Storages such as Google drive and other systems give a variety of options to the users. The mobile clouding system also provides the users to save their data in the storages. For the students, it gives an opportunity to save their written content, online lectures, books and other academic resources in the mobile.

Thus, the MCC escalates the demand for m-learning. This system not only gives benefits to the students but it also gives benefits to the professionals. The important documents in a non-physical form and other presentations can be saved in the cloud storages. Still there is a need to investigate further on the data hacking issue, as the rate of data hacking is increasing and it raises many other serious concerns. Further, researches should be conducted on the security of the MCC.

\section{$4 \quad$ Future Research}

Every day we come to know about new innovative IT systems and other networks which are transforming the life rapidly. The latest information communication technology has integrated deeply into the society. Indeed, the widespread use of MCC has helped the people. However, there are still many research questions in this field that are important and need to be addressed. 
The foremost task for the future researchers is to do more research in the usage of cloud mobile computing and its benefits in a society as a general. The second research is required for the issue of the data security in the cloud computing that by using MCC the security of the users may affect. This will help the users to adopt safe modes to secure their data in their Smartphone.

This means, by pondering on security issues of MCC, other topics like innovations in this field may also be addressed. Besides, security risks are also high because the advancement in the cloud computing technology also enables the hacker to hack the data. Thus, further investigation is required on the security matter as world famous scandals Wiki Leaks, Panama Papers are the worst form of data security breach. Incidents like this, raise the questions that how the MCC enables to protect the data of the users in the storages.

\section{$5 \quad$ References}

[1] Zamani, A. (2014). The Impact of the cloud based m-learning in higher education. International Journal of Advanced Research in Computer Science and Software Engineering, 4(1), 569-574.

[2] Xia, Z., Wang, X., Sun, X., \& Wang, Q. (2016). A secure and dynamic multi-keyword ranked search scheme over encrypted cloud data. IEEE Transactions on Parallel and Distributed Systems, 27(2), 340-352. https://doi.org/10.1109/TPDS.2015.2401003

[3] Singh, A. (2013). Aartinandal, "Neural Cryptography for Secret Key Exchange and Encryption with AES". International Journal of Advanced Research in Computer Science and Software Engineering, 3(5), 376-381.

[4] Sarddar, D., \& Bose, R. (2014). A mobile cloud computing architecture with easy resource sharing. International Journal Current Engineering Technology, 4(3), 1249-1254.

[5] Alghabban, W. G., Salama, R. M., \& Altalhi, A. R. (2016). Mobile Cloud Computing and M-Learning: State of Art.

[6] Al-Adwan, A., \& Smedley, J. (2012). Implementing e-learning in the Jordanian Higher Education System: Factors affecting impact. International Journal of Education and Development using Information and Communication Technology, 8(1), 121.

[7] Boyinbode, O., \& Akintade, F. (2015). A Cloud Based Mobile Learning Interface. In Proceedings of the World Congress on Engineering and Computer Science (Vol. 1).

[8] Ratten, V. (2017). Mobile cloud computing: innovation and creativity perspectives. International. Journal of Technology Marketing, 12(1). https://doi.org/10.1504/ IJTMKT.2017.081514

[9] O'Donnell, A. (2014). Using M-learning as a Means to Promote Self-direction and Engagement in Apprenticeship Theoretical Lessons. Irish Journal of Academic Practice, $3(1), 6$.

[10] Hashemi, M., Azizinezhad, M., Najafi, V., \& Nesari, A. J. (2011). What is mobile learning? Challenges and capabilities. Procedia-Social and Behavioral Sciences, 30, $2477-$ 2481. https://doi.org/10.1016/j.sbspro.2011.10.483

[11] Diabat, B. (2011). The Extent of Acquiring E-Learning Competencies by Faculty Members in Jordan Universities. European Journal of Social Sciences, 27(1), 71-81.

[12] Verma, K., Dubey, S., \& Rizvi, M. (2012). Mobile cloud a new vehicle for learning: mlearning its issues and challenges. International Journal of Science and Applied Information Technology, 1(3). 
Paper-Influence of Cloud Based Mobile Learning Applications on User Experiences: A Review Study...

[13] Gupta, P., \& Gupta, S. (2012). Mobile cloud computing: the future of cloud. International Journal of Advanced Research in Electrical, Electronics and Instrumentation Engineering, 1(3), 134-145.

[14] Seliaman, M. E., \& Al-Turki, M. S. (2012). Mobile learning adoption in Saudi Arabia. Benchmarking, 2358, 2105.

[15] Kureshi, I., Pulley, C., Brennan, J., Holmes, V., Bonner, S., \& James, Y. (2013). Advancing research infrastructure using openstack. International Journal of Advanced Computer Science and Applications, 3(4), 64-70. https://doi.org/10.14569/SpecialIssue. 2013.030408

[16] Behera, S. K. (2013). E-and M-Learning: A comparative study. International Journal on New Trends in Education and Their Implications, 4(3), 65-78.

[17] Wang, L., \& Alexander, C. A. (2014). Telemedicine based on mobile devices and mobile cloud computing. International Journal of Cloud Computing and Services Science, 3(1), 26.

[18] Kundu, A., Banerjee, A., \& Saha, P. (2010). Introducing new services in cloud computing environment. In International Journal of Digital Content Technology and its Applications, AICIT.

[19] Masud, A. H., \& Huang, X. (2013). A cloud based M-learning architecture for higher education. Archives Des Sciences, 66(1), 751-760.

[20] Bahrami, M. (2013). Cloud template, a big data solution. arXiv preprint arXiv:1307.4716.

[21] Jain, S., Srivastava, S., \& Tyagi, A. (2012). Nature of m-learning affecting learning style. National Journal of System and Information Technology, 5(1), 34.

\section{Author}

Osama Harfoushi is with the Department of Business Information Technology, The University of Jordan, Amman, Jordan (o.harfoushi@ju.edu.jo).

Article submitted 21 March 2017. Published as resubmitted by the author 03 May 2017. 